\title{
Desain dan Implementasi Sistem Pembelajaran Jarak Jauh Di Program Studi Sistem Komputer
}

\author{
Muhammad Rozi Yerusalem ${ }^{1)}$, Adian Fatur Rochim ${ }^{2)}$, Kurniawan Teguh Martono ${ }^{2)}$ \\ Program Studi Sistem Komputer Fakultas Teknik Universitas Diponegoro \\ Jalan Prof. Sudharto, Tembalang, Semarang, Indonesia \\ roziyerus@gmail.com
}

\begin{abstract}
ABSTRAK
Teknologi informasi saat ini digunakan pada berbagai bidang seperti pembelajaran. Pembelajaran yang dilakukan biasanya disebut dengan e-learning atau pembelajaran jarak jauh. Pembelajaran ini dilakukan dengan menggunakan media yang memungkinkan peserta didik/mahasiswa dan pengajar/dosen dapat melakukan aktivitas pembelajaran tanpa harus bertatap muka. Universitas Diponegoro memiliki sistem otentikasi terpusat berbasis Lightweight Directory Access Protocol. Sistem otentikasi ini menggunakan username dan password yang terdapat dalam server LDAP. Universitas Diponegoro memiliki sistem informasi akademik yang beralamat di http://sia.undip.ac.id. Sistem informasi akademik ini digunakan mahasiswa untuk pengisian kartu rencana studi setiap semester. Berdasarkan latar belakang tersebut dibangun sebuah sistem pembelajaran jarak jauh yang menggunakan otentikasi login single sign on berbasis LDAP dan terintegrasi dengan sistem informasi akademik.

Metodologi penelitian yang digunakan meliputi studi literatur dan bimbingan, pengambilan data dan analisis, menggunakan metode pengembangan prototyping. Sistem dibuat menggunakan LMS Moodle, ownCloud, dan CAS Server serta LDAP Server Universitas Diponegoro.

Penelitian ini telah dihasilkan sebuah purwarupa sistem pembelajaran jarak jauh berbasis LMS Moodle dan ownCloud yang memiliki otentikasi Single Sign On berbasis CAS Server dan LDAP Server. Moodle telah dikembangkan sehingga dapat melakukan enroll mahasiswa kedalam course sesuai dengan mata kuliah pada kartu rencana studi.
\end{abstract}

Kata Kunci : Pembelajaran Jarak Jauh ,LMS, Moodle, ownCloud, Single Sign On, LDAP

\section{Pendahuluan}

\section{Latar Belakang}

Teknologi informasi saat ini berkembang dengan cepat. Hal ini ditunjukkan dengan penggunaannya dalam berbagai bidang seperti pendidikan. Biasanya pendidikan yang dilakukan dengan cara konvensional yang mengharuskan pengajar dan peserta didik untuk bertatap muka, kini dapat dilakukan tanpa harus bertatap muka dan berada dalam kelas. Teknologi informasi yang digunakan berupa sistem pembelajaran jarak jauh (PPJ). PPJ memungkinkan untuk melakukan pembelajaran secara jarak jauh tanpa terikat jarak, dimanapun dan kapanpun dapat mengakses pembelajaran tersebut.

PPJ memiliki berbagai manfaat seperti menghemat biaya, waktu, efektif dalam penyampaian karena memiliki kemampuan memperbaharui, menyimpan, mendistribusikan, dan membagi materi pengajaran atau informasi. Penerapan $e$ learning akan semakin efektif bila berhubungan dengan usaha yang konsisten dan terintegrasi dari pelajar, lembaga, fasilitator, staff penunjang, dan administrator. ${ }^{[13]}$

Pada tahun 2010, angka partisipasi kasar pendidikan tinggi di Indonesia mencapai 21,6\%. Suatu hasil yang menggembirakan, namun masih jauh dari pencapaian target nasional, yaitu 30\% pada tahun 2015. Dalam PP 17/2010 pasal 118 dinyatakan bahwa PJJ diselenggarakan dengan tujuan meningkatkan perluasan dan pemerataan akses pendidikan, serta meningkatkan mutu dan relevansi pendidikan. Oleh karenanya PJJ memiliki karakteristik terbuka, belajar mandiri, belajar tuntas, menggunakan teknologi informasi dan komunikasi (TIK), dan atau menggunakan teknologi lainnya. Melalui sistem PJJ, setiap orang dapat memperoleh akses terhadap pendidikan berkualitas tanpa harus meninggalkan keluarga, rumah, pekerjaan, dan tidak kehilangan kesempatan berkarir. Sifat masal sistem PJJ dalam mendistribusikan pendidikan berkualitas yang terstandar dengan menggunakan TIK, standarisasi capaian pembelajaran (learning outcomes), materi ajar, proses pembelajaran, bantuan belajar, dan evaluasi pembelajaran, menjadikan pendidikan berkualitas dapat diperoleh berbagai kalangan lintas ruang dan waktu. ${ }^{[13]}$

Proses perkuliahan yang dilaksanakan oleh program studi Sistem Komputer saat ini belum semua mata kuliah menggunakan aplikasi komputer sebagai media penyampaian dalam pembelajaran. Sebagian besar masih dilakukan secara konvensional. Cara konvensional ini, dosen dan mahasiswa harus bertatap muka pada satu ruang dan waktu yang sama.

Universitas Diponegoro memiliki sistem otentikasi terpusat berbasis Lightweight Directory Access Protocol ${ }^{[10]}$. Sistem otentikasi ini menggunakan username dan password yang terdapat dalam server LDAP. Sistem Otentikasi yang dibangun sesuai dengan lingkungan implementasi dan kebutuhan di Universitas Diponegoro memiliki alamat di https://sot.undip.ac.id. Universitas Diponegoro memiliki sistem informasi akademik yang beralamat di http://sia.undip.ac.id. Sistem informasi akademik ini memungkinkan mahasiswa untuk melakukan pengisian kartu rencana studi setiap semester.

Berdasarkan latar belakang diatas penulis mengambil tema tentang desain dan implementasi sistem pembelajaran jarak jauh yang mempunyai ruang lingkup di program studi Sistem Komputer. Desain dan implementasi sistem pembelajaran jarak jauh menggunakan perangkat lunak yang 
berbasis Learning Management System (LMS), Penggunaan sistem Single Sign On (SSO) yang memungkinkan pengajar/dosen dan peserta didik/mahasiswa dapat menggunakan fasilitas menggunakan satu akun yang telah terdaftar. Dosen dan mahasiswa dapat menyimpan berkasberkas kedalam OwnCloud. OwnCloud dapat digunakan untuk berbagi berkas dalam proses pembelajaran jarak jauh. LMS yang dikembangkan dapat memasukkan mahasiswa kedalam courses berdasarkan mata kuliah yang diambil.

LMS yang digunakan adalah Moodle. Moodle merupakan LMS yang mendukung sistem pembelajaran jarak jauh yang memliki berbagai fitur yang memudahkan, diantaranya adalah dapat menyesuaikan jadwal peserta didik/mahasiswa, materi yang dapat diakses secara berulangulang. Penggunaan SSO dapat mengatasi permasalahan akun, karena dengan SSO memungkinkan pengguna dapat melakukan login hanya menggunakan satu akun saja. Hal ini menguntungkan bagi mahasiswa untuk login menggunakan akun yang sudah dimiliki pada sistem informasi akademik.

\section{Tujuan Penelitian}

Tujuan dari penelitian tugas akhir ini adalah membuat sistem pembelajaran jarak jauh yang dapat digunakan peserta didik/mahasiswa, pengajar/dosen untuk melakukan kegiatan perkuliahan yang terintegrasi dengan sistem informasi akademik dan menggunakan otentikasi single sign on.

\section{Batasan Masalah}

Dalam penulisan tugas akhir ini penulis memiliki batasan-batasan sebagai berikut :

1. Penelitian hanya membahas otentikasi menggunakan Single Sign On untuk mengakses SSO Server, Moodle, ownCloud, pendaftaran course mahasiswa berdasarkan Kartu Rencana Studi. Tidak membahas tentang Single Sign Out

2. Menggunakan LMS Moodle versi 2.8 yang berbasis open source.

3. Menggunakan theme Moodle BCU.

4. Sistem ini menggunakan OwnCloud versi 8 berbasis open source.

5. Otentikasi pengguna menggunakan Single Sign On yang berbasis Central Authentication Service dan LDAP Server.

6. LDAP Server yang digunakan adalah Open LDAP Server Universitas Diponegoro

7. Menggunakan CAS Server versi 4.0 berbasis open source

8. Pembuatan plugin Moodle untuk pendaftaran courses Moodle mahasiswa berdasarkan mata kuliah yang diambil masing-masing mahasiswa pada sistem informasi akademik.

9. Data mata kuliah yang diambil mahasiswa dari sistem informasi akademik bukan data sebenarnya (dummy).

10. Sistem ini diimplementasikan dalam bentuk purwarupa.

11. Data mahasiswa berupa username dan password angkatan 2012, 2013, 2014 merupakan data sebenarnya dari program studi Sistem Komputer.
12. Menambahkan data pengguna berupa username dan password kedalam LDAP Server.

\section{LANDASAN TEORI}

\section{Pengertian Pembelajaran Jarak Jauh}

Pembelajaran konvensional yang biasanya

dilaksanakan di sekolah atau perguruan tinggi memiliki sejumlah peraturan sebagai sebuah pendidikan formal. Di dalam kegiatan pembelajarannya terdapat unsur-unsur yang terkait, seperti pembelajar, pengajar, tujuan, materi, metode, media, evaluasi, lingkungan, sarana dan prasarana pembelajaran. Seiring dengan perkembangnya ilmu pengetahuan dan teknologi, khususnya teknologi informasi dan komunikasi (TIK), pembelajaran tidak hanya dilaksanakan di lembaga pendidikan, seperti di sekolah atau perguruan tinggi, dengan cara tatap muka antara pembelajar dengan pembelajar.

Proses pembelajaran pun dibatasi waktu dan ruang dengan empat dinding satu alas dan satu atap, selain itu, pembelajar duduk dalam suatu ruangan pada jam-jam yang ditentukan. Namun dapat pula dilaksanakan dengan cara pembelajaran jarak jauh melalui penggunaan teknologi, seperti komputer dengan internetnya. Pengajar dan pembelajar tidak perlu berada dalam satu tempat yang sama dan dalam waktu yang sama pula, tetapi mereka bisa berada dimana pun dan tidak dibatasi oleh waktu. Beberapa orang ahli mengungkapkan pengertian pembelajaran jarak jauh, diantaranya G. Dogmen, G. Mackenzie, E. Christensen, dan P. Rigby, O. Peter, M. Moore, B. Holmeberg.

Menurut Dogmen ciri-ciri pembelajaran jarak jauh adalah adanya organisasi yang mengatur cara belajar mandiri, materi pembelajaran disampaikan melalui media, dan tidak ada kontak langsung antara penngajar dengan pembelajar. Mackenzie, Christensen, dan Rigby mengatakan pendidikan jarak jauh (PJJ) merupakan metode pembelajaran yang menggunakan korespondensi sebagai alat untuk berkomunikasi antara pembelajar dengan pengajar. Salah satu bentuk pendidikan jarak jauh adalah Sekolah Korespondensi. Korenspondensi merupakan metode pembelajaran menggunakan korespondensi sebagai alat untuk berkomunikasi antara pembelajar dengan pengajar. Karakteristiknya antara lain pembelajar dan pengajar bekerja secara terpisah, namun keduanya dipersatukan dengan korespondensi.

Korespondensi diperlukan agar terjadi interaksi antara pembelajar dan pengajar. Menurut mereka karakteristik pembelajaran jarak jauh adalah pembelajar dan pengajar bekerja secara terpisah, pembelajar dan pengajar dipersatukan melalui korespondensi, dan perlu adanya interaksi antara pembelajar dan pengajar. Pendidikan jarak jauh itu merupakan bentuk pendidikan yang memberikan kesempatan kepada pembelajarnya untuk belajar secara terpisah dari pengajarnya. Namun ada kemungkinan untuk acara pertemuan antara pengajar dan pembelajar hanya dilakukan kalau ada peristiwa yang istimewa atau untuk melakukan tugas-tugas tertentu saja. Peter memberikan batasan pembelajaran jarak jauh sebagai metode penyampaian ilmu, keterampilan, dan sikap yang dipengaruhi cara-cara mengelola suatu industri. 
Metode seperti itu dapat disebutkan sebagai mengindustrialisasikan cara belajar dan mengajar. Sistem pendidikan jarak jauh dikembangkan dan dikelola dengan mengadakan pembagian tugas yang jelas antara yang mengembangkan, memproduksi, mendistribusikan materi pembelajaran, dan yang mengelola kegiatan pembelajaran. Materi pembelajaran diproduksi dalam jumlah banyak dengan menggunakan teknologi yang maju, kemudian didistribusikan kepada pengguna secara luas. Materi pembelajaran yang diproduksi dalam jumlah banyak dengan mutu yang tinggi itu memberikan kemungkinan untuk membelajarkan pembelajar dalam jumlah banyak pula pada saat yang sama di mana pun mereka berada. Peter menambahkan ciri lainnya bahwa pendidikan jarak jauh seolah-olah dikelola seperti industri.

Pendapat Peter ini ada yang mendukung, tetapi ada pula yang menolaknya. Di antara yang menolak teori industrialisasi itu adalah Baath, karena teori industrialisasi itu tidak dapat diterapkan pada pendidikan jarak jauh yang kecil, dan pendidikan jarak jauh tidak menggunakan materi pembelajaran yang diproduksi dalam jumlah besar. Karena itu pendapat Peter itu dianggap tidak dapat dimasukkan ke dalam batasan umum sistem pendidikan jarak jauh. Batasan dari Peter ini mengandung beberapa karakteristik yaitu, pertama dimanfaatkannya teknologi sebagai media yang diproduksi dalam jumlah banyak namun tetap dengan mutu yang tinggi.

Kedua, pendidikan dapat diberikan secara massal. Ketiga, materi pembelajaran dirancang, dikembangkan, diproduksi, dibagikan, dan dikelola dalam kegiatan pembelajaran oleh orang yang berbeda-beda. Moore mengajukan batasan pembelajaran jarak jauh sebagai metode pembelajaran yang memberikan kesempatan kepada pembelajar untuk belajar secara terpisah dari kegiatan mengajar pengajar, sehingga komunikasi antara pembelajar dan pengajar harus dilakukan dengan bantuan media, seperti media cetak, elektronik, mekanis, dan peralatan lainnya. Batasan yang menonjol dari Moore itu adalah terpisahnya pembelajar dan pengajar dalam proses pembelajaran, dan digunakannya media untuk komunikasi antara pembelajar dan pengajar.

Sedangkan bersama Kearsly, Moore mengatakan pembelajaran jarak jauh adalah belajar yang direncanakan di tempat lain atau di luar tempatnya mengajar. Oleh karena itu, diperlukan teknik-teknik khusus dalam mendesain materi pembelajaran, teknikteknik khusus pembelajaran, metodologi khusus komunikasi melalui berbagai media, dan penataan organisasi serta administrasi yang khusus pula. Menurut Dogmen pembelajaran jarak jauh adalah pembelajaran yang menekankan pada cara belajar mandiri (self study). . ${ }^{[8]}$

Beberapa istilah yang digunakan dalam konteks penyelenggaraan program pendidikan jarak jauh pada jenjang pendidikan tinggi sebagai berikut:

1. Program pendidikan jarak jauh pada jenjang pendidikan tinggi merupakan program yang menerapkan proses pembelajaran secara jarak jauh melalui penggunaan berbagai TIK.

2. Materi ajar PJJ adalah bahan ajar yang dikembangkan dan dikemas dalam beragam bentuk berbasis TIK yang dapat digunakan dalam proses belajar.
3. Belajar mandiri adalah proses belajar yang didasarkan pada inisiatif peserta didik dengan bantuan minimal dari pihak lain

4. Bantuan belajar adalah segala bentuk kegiatan pendukung yang dilaksanakan oleh pengelola PJJ untuk membantu kelancaran proses belajar peserta didik berupa pelayanan akademik dan administrasi, maupun pribadi, berbasis TIK

5. Tutorial adalah bentuk bantuan belajar akademik yang dapat dilaksanakan secara tatap muka maupun melalui pemanfaatan TIK

6. Evaluasi hasil belajar peserta didik adalah penilaian yang dilakukan terhadap hasil proses belajar peserta didik dalam bentuk tatap muka dan jarak jauh berbasis TIK.

7. Evaluasi hasil belajar secara tatap muka adalah bentuk evaluasi yang dilakukan dengan pengawasan langsung.

8. Evaluasi hasil belajar secara jarak jauh adalah evaluasi dengan atau tanpa pengawasan langsung terhadap tugas yang dikerjakan oleh peserta didik secara mandiri dan berbasis TIK.

9. Praktik adalah latihan keterampilan penerapan teori dengan pengawasan langsung menggunakan sarana dan prasarana yang memenuhi standar minimum.

10. Praktikum adalah tugas terstruktur dan berhubungan dengan validasi fakta atau hubungan antar fakta, yang mendukung capaian pembelajaran (learning outcomes) secara utuh sesuai dengan yang disyaratkan dalam kurikulum.

11. Pengalaman lapangan adalah tugas yang dilakukan dalam lingkungan kerja sesuai dengan yang disyaratkan dalam kurikulum serta dilaksanakan dengan pengawasan langsung.

12. Unit sumber belajar adalah pendukung penyelenggaraan program PJJ yang berada di luar kantor pusat, di daerah, dan atau di wilayah jangkauan.

13. Sistem pendidikan tinggi tatap muka adalah pendidikan tinggi yang menyelenggarakan proses pembelajaran melalui pertemuan langsung antara tenaga pendidik dengan pesertadidik.

14. E-learning adalah proses belajar dan pembelajaran yang memanfaatkan paket informasi elektronik untuk kepentingan pembelajaran dan pendidikan, yang diakses oleh peserta didik, kapan saja dan dimana saja berbasis TIK.

\section{Prinsip Pendidikan Jarak Jauh}

1. Akses

Keinginan untuk meningkatkan akses terhadap pendidikan telah menjadi pemicu utama untuk menyelenggarakan sistem PJJ. Berdasarkan paradigma akses ini, sistem PJJ menerapkan prinsip industrialisasi yaitu sifat pendidikan yang massal untuk mencapai keuntungan ekonomis. Pendidikan fleksibel: berbasis TIK lintas ruang dan waktu. Meningkatkan keterbukaan pendidikan, meminimalkan keterbatasan waktu, tempat, dan kendala ekonomi maupun demografi seseorang untuk memperoleh pendidikan.

2. Pemerataan

Prinsip keadilan dan kesamaan hak untuk memperoleh kesempatan berpartisipasi dalam proses pendidikan, bagi siapa saja tanpa batasan kendala apapun Sistem pendidikan yang fleksibel lintas ruang, waktu, dan 
sosioekonomi dalam membuka akses terhadap pendidikan menyebabkan sistem PJJ menarik bagi banyak kalangan. Setiap orang dapat memperoleh pendidikan berkualitas tanpa harus meninggalkan keluarga, rumah, pekerjaan, dan tidak kehilangan kesempatan berkarir Sistem pendidikan tinggi model supermarket, yang sangat terbuka, sangat dipengaruhi oleh kebutuhan pembeli, dan sangat fleksibel untuk memenuhi beragam kebutuhan peserta didik maupun pemangku kepentingan.

3. Kualitas

Berdasarkan karakteristik proses pembelajaran yang terjadi dalam sistem PJJ, kurikulum, materi ajar, proses pembelajaran, dan bahan ujian biasanya dikemas dalam bentuk standar untuk didistribusikan lintas ruang dan waktu dengan menggunakan berbagai TIK. Untuk mendukung pencapaian kualitas yang standar, program PJJ sangat tergantung pada pemanfaatan fasilitas belajar bersama berdasarkan kemitraan antar institusi.

\section{Tenaga Pendidik Pada Pendidikan Jarak Jauh}

Di lingkungan Lemhannas RI diangkat Tenaga Ahli. Jumlah Tenaga Ahli yang diangkat sesuai dengan kebutuhan diatur menurut Peraturan Gubernur Lemhannas RI tersendiri. Tenaga Ahli mempunyai tugas:

1. Sebagai tenaga pengajar

2. Sebagai tenaga pengkaji

3. Sebagai penanggung jawab pembinaan peserta PPRA/PPSA

4. Sebagai staf ahli gubernur lemhannas Republik Indonesia (RI).

5. Melaksanakan tugas lain yang ditugaskan oleh Gubernur Lemhannas RI.

Penggunaan Tenaga Ahli Lemhannas RI dalam rangka mendukung pelaksanaan pengkajian dikoordinasikan oleh Deputi Bidang Pengkajian Strategik. Tenaga Pengkaji Lemhannas RI dalam kegiatan sehari-hari dikoordinasikan oleh Deputi Bidang Pengkajian Strategik. Penggunaan Tenaga Ahli Lemhannas RI dalam rangka mendukung pelaksanaan pemantapan nilai-nilai kebangsaan dikoordinasikan oleh Deputi Bidang Pemantapan Nilai-Nilai Kebangsaan. Adapun sebagai pendidik PJJ paling sedikit meliputi:

1. Perancang program pembelajaran.

2. Penyusun dan/atau pengembang materi ajar dan media.

3. Produser materi ajar dan media.

4. Penyebar luas dan/atau pengunggah materi ajar dan media.

5. Penulis soal, tugas, dan/atau evaluasi hasil belajar.

6. Posen pengampu dan pemelihara mata kuliah.

7. Tutor.

8. Pembimbing praktik dan/atau tugas akhir

9. Penguji.

10. Pengelola di pusat maupun di wilayah jangkauan

11. Administrator ujian

12. Laboran dan/atau teknisi

13. Pranata teknologi informasi dan komunikasi

14. Pustakawan

\section{Penyelenggaraan Pendidikan Jarak Jauh}

Penggunaan metode pembelajaran interaktif berdasarkan konsep belajar mandiri, terstruktur, dan terbimbing yang menggunakan berbagai sumber belajar dan dengan dukungan bantuan belajar serta fasilitas pembelajaran. Menjadikan media pembelajaran sebagai sumber belajar yang lebih dominan dari pada pendidik.

\section{Kurikulum Program Pendidikan Jarak Jauh}

1. PJJ dapat diselenggarakan dengan lingkup mata pelajaran atau mata kuliah, program studi, atau satuan pendidikan.

2. Kurikulum program PJJ memiliki beban studi dan ruang lingkup yang sama dengan kurikulum program studi yang diselenggarakan dengan modus tatap muka, namun memberikan keluwesan belajar bagi peserta didik. Hal ini ditunjukkan dengan kesamaan capaian pembelajaran (learning outcomes) untuk setiap mata kuliah/mata pelajaran atau program studi.

3. Profil dan capaian pembelajaran lulusan program PJJ adalah sama dengan profil dan capaian pembelajaran lulusan program pendidikan tatap muka yang sesuai.

4. Proses pembelajaran jarak jauh dilakukan secara terstruktur dengan memanfaatkan TIK termasuk layanan akademik yang diberikan dosen/tutor sehingga memotivasi peserta didik untuk belajar dengan memanfaatkan beragam sumber belajar secara terintegrasi.

5. Evaluasi hasil belajar harus dapat mencerminkan tingkat kemampuan peserta didik melalui mekanisme ujian secara tatap muka atau secara jarak jauh dengan pengawasan langsung.

\section{Ragam Proses Belajar Pendidikan Jarak Jauh}

1. Belajar mandiri: proses pembelajaran yang diinisiasi oleh peserta didik dalam periode tertentu. Dosen menyiapkan beragam tugas dan pemicu yang dapat membantu peserta didik belajar secara mandiri.

2. Belajar terbimbing/terstruktur: proses pembelajaran yang disediakan oleh perguruan tinggi untuk membantu proses belajar peserta didik dalam bentuk tutorial tatap muka dan tutorial elektronik. Dengan mengandalkan bimbingan dosen/tutor secara langsung maupun virtual, secara residensial maupun non-residensial.

3. Tutorial tatap muka: proses pembelajaran jarak jauh dilaksanakan dengan mempersyaratkan adanya tutorial/pembimbingan tatap muka langsung (atau termediasi sinkron) kepada peserta didik untuk beragam mata kuliah.

4. Tutorial elektronik: proses pembelajaran jarak jauh yang dilaksanakan dengan mempersyaratkan adanya interaksi peserta didik dengan dosen/tutor, atau peserta didik dengan peserta didik yang termediasi oleh media berbasis TIK.

5. Bantuan lainnya (koresponden, telepon, dan faksimile).

\section{Single Sign On}

Teknologi Single Sign On (SSO) adalah teknologi yang mengizinkan pengguna jaringan agar dapat mengakses sumber daya dalam jaringan hanya dengan menggunakan satu akun saja. Teknologi ini sangat diminati, khususnya dalam jaringan yang sangat besar dan bersifat heterogen (di saat 
sistem operasi serta aplikasi yang digunakan oleh komputer adalah berasal dari banyak vendor, dan pengguna diminta untuk mengisi informasi dirinya ke dalam setiap platform yang berbeda tersebut yang hendak diakses oleh pengguna). Dengan menggunakan SSO, seorang pengguna hanya cukup melakukan proses autentikasi sekali saja untuk mendapatkan izin akses terhadap semua layanan yang terdapat di dalam jaringan. ${ }^{[4]}$

\section{LMS (Learning Management System) atau CMS (Course Management System)}

Merupakan aplikasi perangkat lunak yang digunakan oleh kalangan pendidik, baik universitas/perguruan tinggi dan sekolah sebagai media pembelajaran online berbasis internet. Dengan menggunakan LMS dosen/guru/instruktur dapat mengelola program/kelas dan bertukar informasi dengan siswa. Selain itu, akses terhadap materi pembelajaran yang berlangsung dalam kurun waktu yang telah ditentukan juga dapat dilakukan.

\section{Moodle}

Moodle merupakan program open source yang paling terkenal diantara program-program e-learning yang ada, misalnya ATutor, eLeaPTM LEARNING MANAGEMENT SYSTEM LMS, dan seterusnya. Aplikasi Moodle ini dikembangkan pertama kali oleh Martin Douglamas pada Agustus 2002 dengan Moodle versi 1.0. Moodle bersifat open source, sehingga Moodle dapat diunduh secara gratis dari situs resminya http://www.Moodle.org dan dapat dimodifikasi oleh siapa saja dengan lisensi GNU (General Public License). ${ }^{[1]}$

\section{ownCloud}

ownCloud adalah aplikasi yang digunakan untuk sinkronisasi berkas yang bersifat open source. ownCloud mendukung membagikan berkas dan folder yang terdapat pada komputer dan menyesuaikannya dengan Server ownCloud. ${ }^{[9]}$

\section{PHP}

PHP memiliki kepanjangan Hypertext Preprocessor digunakan secara luas dan bersifat open source digunakan secara bebas. Umumnya digunakan untuk membangun website dan dapat ditempelkan kedalam HTML. Kode PHP dieksekusi pada Server yang kemudian dikirim ke klien . Klien akan menerima hasil dari menjalankan sekrip itu, tapi tidak akan tahu apa kode yang sesungguhnya. ${ }^{[7]}$

XML

XML memiliki kepanjangan Extensible Markup Language. XML memuat bentuk, label, struktur dan informasi yang dilindungi dengan menggunakan simbol yang melekat pada teks yang disebut dengan markah. Markah ini menampilkan sejumlah informasi dengan cara tertentu, mengidentifikasi bagian-bagian dan bagaimana bagianbagian ini terhubung satu dengan yang lain. ${ }^{[1]}$

\section{LDAP Server}

LDAP adalah sebuah protokol yang mengatur mekanisme pengaksesan layanan direktori (Directory Service) yang dapat digunakan untuk mendeskripsikan banyak informasi seperti informasi tentang people, organizations, roles, services dan banyak entitas lainnya. LDAP menggunakan model client-server, dimana client mengirimkan identifier data kepada Server menggunakan protokol TCP/IP dan Server mencoba mencarinya pada DIT (Directory Information Tree) yang tersimpan di server. Bila di temukan maka hasilnya akan dikirimkan ke client tersebut namun bila tidak maka hasilnya berupa pointer ke server lain yang menyimpan data yang dicari. ${ }^{[6]}$

\section{Program Pendukung \\ Web Server}

Web Server berfungsi sebagai sebuah program yang menjadikan komputer merespon untuk menerima HTTP (Hyper Text Transfer Protocol) yang diminta oleh client. Sehingga aplikasi-aplikasi berbasis web dapat berjalan.

\section{MySQL Basis Data Server}

MySQL adalah sebuah perangkat lunak sistem manajemen basis data SQL yang multithread, multi-user, MySQL adalah Relational Database Management System (RDBMS) yang didistribusikan secara gratis dibawah lisensi GPL (General Public License). Dimana setiap orang bebas untuk menggunakan MySQL, namun tidak boleh dijadikan produk turunan yang bersifat closed source atau komersial. MySQL sebenarnya merupakan turunan salah satu konsep utama dalam database sejak lama, yaitu SQL (Structured Query Language). ${ }^{[5]}$

\section{Central Authentication Service (CAS)}

CAS adalah protokol single sign on untuk web. CAS memiliki fungsi untuk mengizinkan pengguna untuk mengakses multi aplikasi hanya dengan menggunakan satu kali login. Server CAS dan klien terdiri dari dua komponen fisik dari arsitektur sistem CAS yang berkomunikasi melalui berbagai protokol . Server CAS adalah Java servlet dibangun di Spring Framework yang tanggung jawab utama adalah untuk mengotentikasi pengguna dan memberikan akses ke layanan CAS diaktifkan, biasa disebut klien CAS, dengan mengeluarkan dan validasi tiket. Sesi SSO dibuat ketika Server mengeluarkan pemberian Ticket Granting Tickets (TGT) untuk pengguna setelah berhasil login. Sebuah layanan Service Tickets (ST) dikeluarkan untuk layanan permintaan pengguna melalui browser pengalihan menggunakan TGT sebagai token. ST selanjutnya divalidasi pada Server CAS melalui komunikasi back-channel. Interaksi ini dijelaskan secara rinci dalam dokumen CAS Protocol.

Istilah klien CAS memiliki dua arti yang berbeda dalam penggunaan umum nya. Seorang klien CAS adalah aplikasi CAS - enabled yang dapat berkomunikasi dengan Server melalui protokol didukung. Seorang klien CAS juga paket perangkat lunak yang dapat diintegrasikan dengan berbagai platform perangkat lunak dan aplikasi untuk berkomunikasi dengan Server CAS melalui beberapa protokol otentikasi (misalnya CAS, SAML, OAuth). CAS klien mendukung sejumlah platform perangkat lunak dan produk telah dikembangkan. ${ }^{[3]}$

\section{Metode Prototyping}

Prototyping adalah proses iterative dalam pengembangan sistem dimana requirement diubah ke dalam sistem yang bekerja (working system) yang secara terus menerus diperbaiki melalui kerjasama antara pengguna dan analis. Prototype juga bisa dibangun melalui beberapa tool pengembangan untuk menyederhanakan proses. ${ }^{[2]}$ 


\section{Perancangan Sistem}

\section{Analisis Kebutuhan}

Mengumpulkan kebutuhan untuk mengidentifikasi kebutuhan perangkat lunak yang dibutuhkan.

\section{Kebutuhan Pengguna}

Kebutuhan pengguna berdasarkan penelitian yang

dilakukan menghasilkan kebutuhan sebagai berikut :
1. Admin
2. Pengajar/Dosen
3. Staff Kependidikan
4. Mahasiswa

\section{Kebutuhan Perangkat Lunak Yang Digunakan}

Sistem yang dibangun membutuhkan perangkat lunak dalam pengembangannya. Berikut ini adalah perangkat lunak yang digunakan dalam membangun sistem.

a. Microsoft Windows 8

Sistem operasi digunakan untuk menjalankan aplikasi Oracle VM Virtual Box, Winscp, Notepad ++.

b. Oracle VM Virtual Box Aplikasi ini digunakan sebagai komputer virtual yang dikonfigurasi untuk membuat Server berbasis sistem operasi linux.

c. Linux Ubuntu 14.04 Desktop Sistem operasi ini digunakan sebagai komputer server virtual yang berjalan dan dikonfigurasi melalui Oracle VM Virtual Box.

d. Linux Ubuntu 12.04 Desktop Sistem operasi ini digunakan sebagai komputer server virtual yang berjalan pada Oracle VM Virtual Box.

e. LAMPP

f. Winscp Perangkat lunak yang digunakan untuk menghubungkan komputer dengan host (komputer server virtual) untuk mengirim berkas.

g. PHPLdapadmin Perangkat lunak yang digunakan untuk memudahkan mengelola pengguna dalam Open LDAP Server.

h. PHPmyadmin Perangkat lunak yang digunakan sebagai antarmuka untuk engine basis data Mysql.

i. $\quad$ Notepad ++ Perangkat lunak yang digunakan sebagai editor untuk melakukan pengodean sistem.

j. Microsoft Office Word dan Visio Digunakan untuk penulisan laporan.

\section{Kebutuhan Perangkat Keras Yang Digunakan}

1. Laptop Asus N46VJ 64-bit dengan sistem operasi Windows 8.

2. Mouse

\section{Pembuatan Purwarupa}

Membuat purwarupa dari kebutuhan. Purwarupa menggambarkan kebutuhan sistem yang diinginkan. Pembuatan purwarupa dengan mockup. Mockup adalah sesuatu yang digunakan untuk mengajar, demonstrasi, evaluasi desain, promosi atau keperluan lain. Mockup mendemonstrasikan sebagian besar fungsi sistem perangkat lunak dan memungkinkan pengujian desain sistem perangkat lunak. Iterasi terjadi pada pembuatan purwarupa sampai sistem yang dibangun sesuai dengan kebutuhan. Berikut ini adalah pembuatan purwarupa meliputi :

\section{Perancangan Pembelajaran}

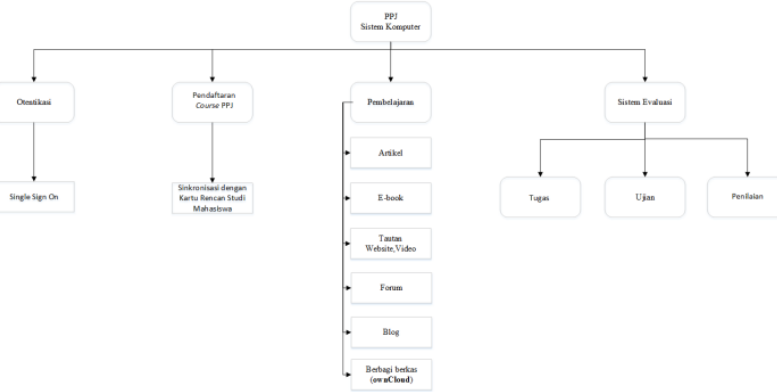

Gambar 3.1 Bagan rancangan pembelajaran jarak jauh Bagan rancangan sistem pembelajaran jarak jauh pada gambar 3.1 menjelaskan rancangan sistem pembelajaran jarak jauh secara umum di program studi Sistem Komputer. Penelitian ini akan berfokus pada otentikasi menggunakan Single Sign On untuk mengakses SSO Server, Moodle, ownCloud, pendaftaran course mahasiswa berdasarkan Kartu Rencana Studi.

Perancangan Otentikasi dan Pendaftaran Course Moodle Mahasiswa Berdasarkan Basis Data Sistem Informasi Akademik

Gambar 3.2 menjelaskan sistem yang akan dibangun. Sistem pemebelajaran jarak jauh yang diinginkan menggunakan otentikasi berbasis single sign on. Kemudian pengguna dapat langsung menuju halaman beranda aplikasi web. Terdapat dua tautan web, yaitu Moodle dan ownCloud, Jika memilih tautan Moodle. Pengguna, khususnya mahasiswa dapat mengikuti course sesuai dengan mata kuliah yang diambil sesuai dengan masing-masing sks mahasiswa.

Moodle mengambil data dari basis data server sistem informasi akademik. Mahasiswa sebelumnya telah mengambil mata kuliah sesuai dengan sks yang diperbolehkan melalui sistem informasi akademik setiap semesternya yang disebut Kartu Rencana Studi. Kartu Rencana Studi (KRS) adalah kartu yang berisi rencana pengambilan mata kuliah pada semester yang akan ditempuh. Mahasiswa dapat mengikuti pemebelajaran jarak jauh yang dilengkapi dengan materi dari pengajar/dosen. Pengajar/dosen dapat memberikan materi berupa teks/artikel/berkas berupa pdf serta dari blog/website yang dimiliki oleh pengajar/dosen. Jika pengguna memilih tautan ownCloud maka akan diarahkan langsung menuju halaman beranda ownCloud.

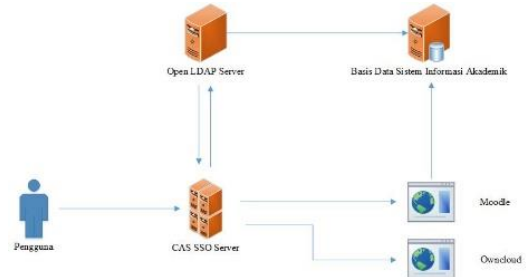

Gambar 3.2 Gambar Perancangan Single Sign On menggunakan Open Ldap Server dan CAS Server. 
Proses otentikasi ini menyocokkan atribut pengguna dengan atribut yang ada di openldap server menggunakan CAS Server. CAS menyimpan atribut berupa username dan memberikan tiket kepada user yang memiliki akun di openldap. Tiket ini digunakan apabila pengguna akan masuk kedalam aplikasi lainnya, sehingga pengguna dapat masuk hanya menggunakan satu kali login. Pengguna dapat login satu kali dan dapat masuk kedalam Moodle dan ownCloud.

\section{Perancangan LMS Moodle dengan Basis Data Sistem Informasi Akademik}

Moodle dapat menampilkan course sesuai dengan jumlah sks yang diambil oleh mahasiswa. Mahasiswa mengambil SKS (satuan kredit semester) setiap semester pada sistem informasi mahasiswa. Dibawah ini adalah gambar hubungan antara LMS Moodle dengan Sistem Informasi Akademik.

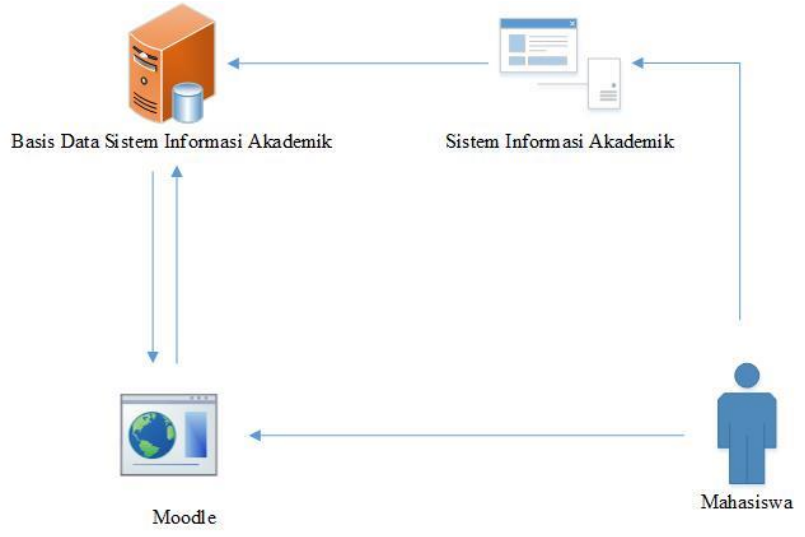

Gambar 3.3 Hubungan antara Moodle dengan sistem informasi akademik

Gambar 3.3 menunjukkan bahwa sistem yang dibangun memiliki fitur utama yaitu Mahasiswa dapat melihat course sesuai dengan mata kuliah yang diambil saat pengisian Kartu Rencana Studi. Mahasiswa tidak perlu melakukan permintaan enroll. Course yang sudah dibuat dapat langsung digunakan oleh mahasiswa. Course ini merupakan mata kuliah yang tersedia dalam sistem informasi akademik dan diambil oleh masing-masing mahasiswa. Sehingga mahasiswa satu dengan mahasiswa lain dapat berbeda jumlah course yang dimiliki.

\section{Rancangan Tampilan login SSO Server}

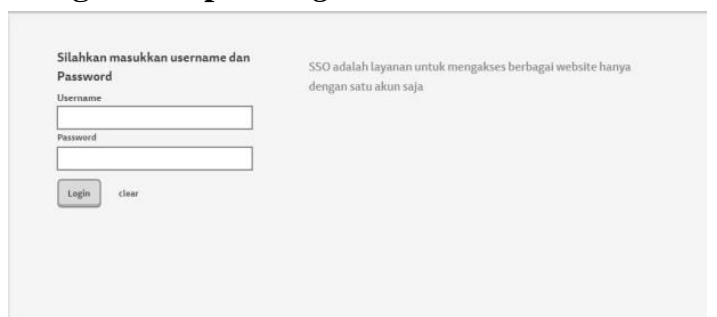

Gambar 3.4 Gambar rancangan tampilan halaman login SSO Server.

\section{Rancangan Tampilan Beranda SSO Server}

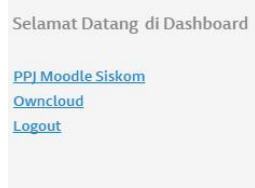

Gambar 3.5 Gambar rancangan tampilan beranda SSO Server

\section{Rancangan Tampilan plugin}

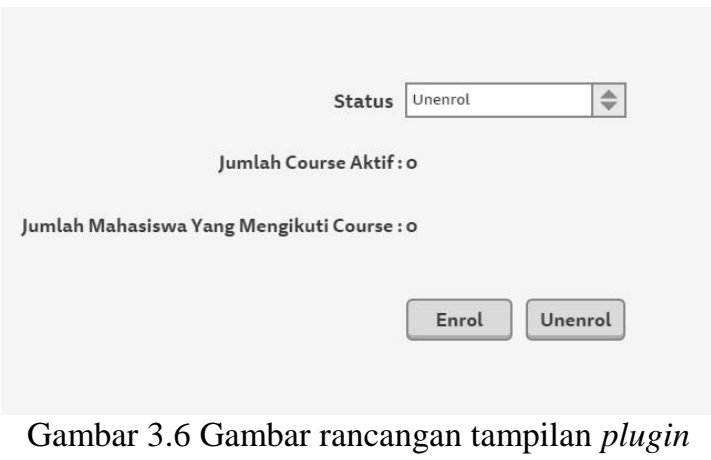

\section{Diagram Alir Sistem}

Sistem ini dikembangkan dengan menggunakan diagram alir. Diagram menunjukkan bagaimana mekanisme sistem berjalan.

\section{Diagram Alir Login Single Sign On}

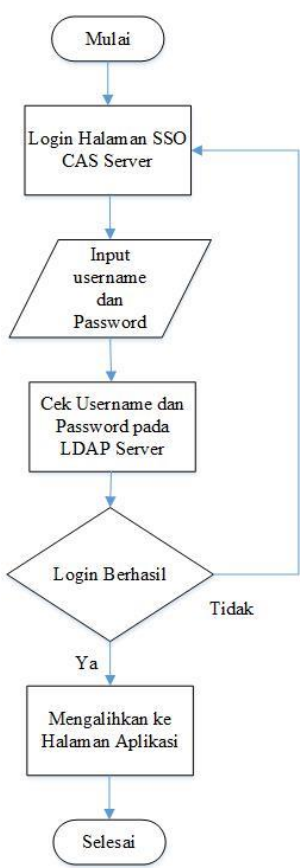

Gambar 3.7 Diagram Alir Login Single Sign On

Gambar 3.7 menunjukkan bahwa pada mekanisme login single sign on. Pengguna membuka halaman login single sign on. Kemudian mengisi username dan password. Username dan password ini akan dibandingkan dengan username dan password yang ada dalam basis data LDAP. 
Jika sesuai maka akan memberikan kembalian nilai true. Sehingga pengguna akan diarahkan ke halaman menu yang terdapat menu tautan aplikasi. Jika tidak maka pengguna akan diarahkan kembali ke halaman login sso.

\section{Diagram Alir LMS Moodle dengan Basis Data Sistem Informasi Akademik}

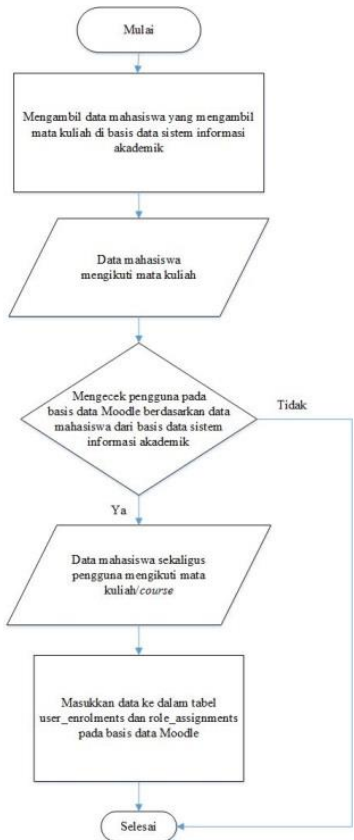

Gambar 3.8 Diagram Alir Alir LMS Moodle dengan Basis Data Sistem Informasi Akademik

Gambar 3.8 menunjukkan bagaimana pengguna yang berperan sebagai mahasiswa didaftarkan sebagai mahasiswa yang mengikuti course Moodle. Mahasiswa ini sebelumnya telah mengambil mata kuliah dalam pengisian kartu rencana studi. Data mahasiswa yang mengambil mata kuliah akan diakses melalui Moodle. Kemudian data mahasiswa yang mengambil mata kuliah akan dicocokkan dengan pengguna yang memiliki hak mahasiswa.. Sehingga didapatkan pengguna mahasiswa yang mengambil mata kuliah. Kemudian course yang didapatkan berasal dari mata kuliah yang diambil mahasiswa. Mahasiswa dengan course yang dimiliki disimpan dalam tabel user_enrolments dan role_assignments pada basis data Moodle, sehingga proses pendaftaran mahasiswa mengikuti course Moodle berdasarkan data mata kuliah yang diambil selesai.

\section{Memperbaiki Purwarupa}

Proses mengembangkan purwarupa sesuai dengan kebutuhan yang sebenarnya. Pada tahap ini dilakukan perbaikan pada purwarupa yang telah dirancang.

\section{IMPLEMENTASI DAN PENGUJIAN}

\section{Implementasi}

Pembuatan dilakukan dengan melakukan tahapantahapan berikut ini :

Konfigurasi dan Instalasi Server pada Virtual Box

Penelitian ini menggunakan 2 buah Server, sebagai berikut:
1. Server 1

Digunakan untuk instalasi direktori LDAP dan CAS Server, pada Server virtual ini diberi nama Server

2. Server 2

Digunakan untuk instalasi aplikasi web, diberi nama webapp. Aplikasi web yang diletakkan di server 2 adalah Moodle dan ownCloud.

Konfigurasi untuk menghubungkan Open LDAP Server dan CAS Server

Konfigurasi untuk menghubungkan Openldap Server dan CAS Server dilakukan dengan mengubah kode pada berkas deployerConfigContext.xml

\section{Konfigurasi menghubungkan Moodle dengan CAS Server Konfigurasi OwnCloud dengan CAS Server}

Konfigurasi untuk menghubungkan Openldap Server dan CAS Server dilakukan dengan mengubah kode pada berkas deployerConfigContext.xml

Membuat tabel untuk plugin enroll mahasiswa sesuai dengan KRS

Untuk membuat plugin yang dapat enroll mahasiswa sesuai dengan KRS maka diperlukan basis data untuk menyimpan beberapa pengaturan yang diperlukan. Pembuatan tabel basis data menggunakan XML. XML digunakan karena Moodle mendukung plugin dengan mengintegrasikan tabel melalui XML.

Membuat antarmuka plugin untuk enroll mahasiswa sesuai dengan KRS

Antarmuka digunakan pengguna untuk berinteraksi dengan plugin disesuaikan dengan kebutuhan.

\section{Membuat Sekrip Untuk Menambahkan Username Dan Password Mahasiswa Kedalam LDAP Server}

Untuk menambahkan username dan password menggunakan kode program seperti dibawah ini. Jika menggunakan alamat LDAP server http://sot.undip.ac.id tidak dapat terhubung maka digunakan alamat IP 192.168.19 dengan port 389. Menambahkan data pengguna menggunakan bahasa pemrograman PHP.

\section{Hasil Impelementasi}

\section{Hasil Pembuatan Single Sign On}

Berikut ini merupakan hasil dari pembuatan otentikasi yang menggunakan CAS Server dengan menggunakan LDAP Server. Gambar 4.21 menunjukkan bahwa SSO Server dapat diakses di alamat https://elearning.siskom.local:8443/cas/login. Pengguna menggunakan username dan password yang dimiliki untuk login.

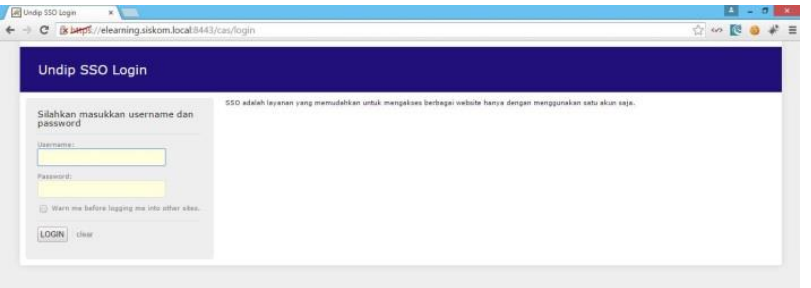

Gambar 4.21 Tampilan login dihalaman SSO Server. 
Jika pengguna login menggunakan username dan password yang salah maka muncul pesan "Invalid Credentials" seperti yang ditunjukkan pada gambar 4.22. Pesan ini memiliki arti bahwa pengguna tidak memliki ijin untuk masuk kedalam sistem. Sedangkan jika pengguna belum pernah login dan mengakses SSO Server maka akan diarahkan menuju halaman login SSO Server.

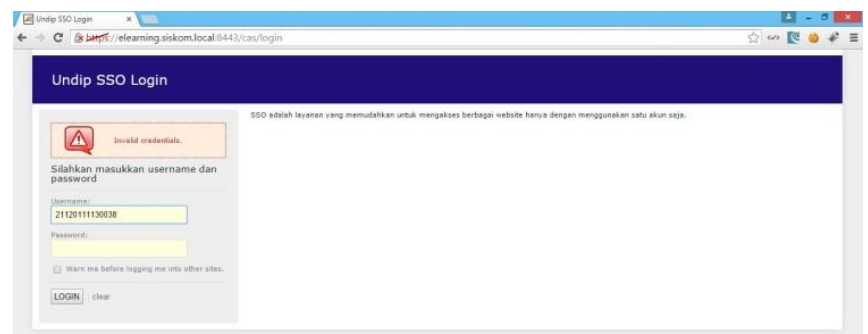

Gambar 4.22 Tampilan jika pengguna salah memasukkan username atau password.

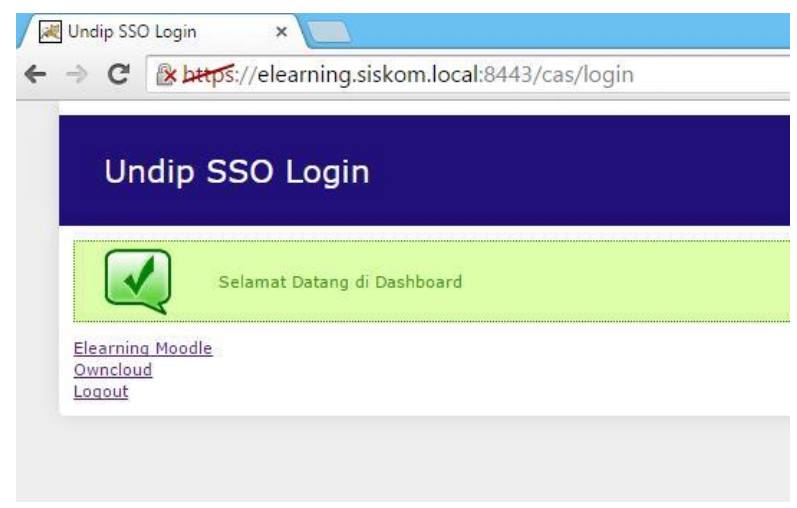

Gambar 4.23 Tampilan jika pengguna berhasil login

Pengguna yang memasukkan username dan password yang cocok dengan username dan password yang berada pada LDAP Server diarahkan menuju halaman yang menampilkan menu berisi tautan Moodle, ownCloud. Kemudian pengguna dapat login kehalaman Moodle atau ownCloud dengan mengklik tautan tersebut. Pada Moodle jika baru pertama kali mengakses maka langsung diarahkan pada halaman yang digunakan untuk melengkapi data pengguna. Sedangkan jika sudah pernah mengakses dan melengkapi data pengguna maka diarahkan halaman beranda yang berisi course yang diikuti. Jika belum mengikuti course muncul pesan kursus tidak ada.

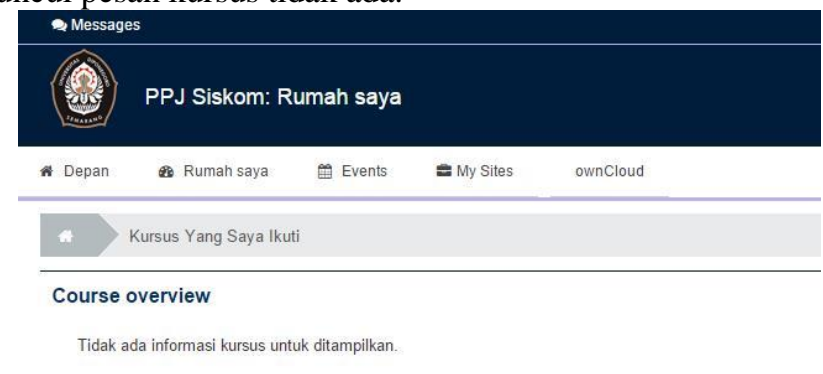

Gambar 4.24 Tampilan pengguna berhasil login Moodle

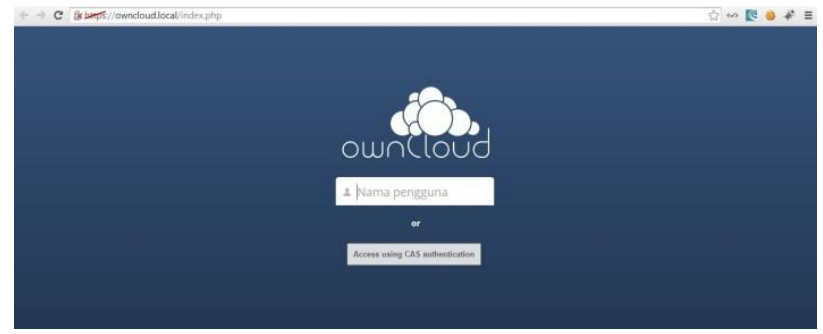

Gambar 4.25 Tampilan login ownCloud

Pengguna yang mengklik tautan ownCloud akan diarahkan menuju halaman login ownCloud. Namun, ownCloud tidak langsung melakukan otentikasi tetapi menampilkan halaman login yang berisi pilihan login menggunakan CAS atau login biasa. Jika pengguna mengklik tombol seperti pada gambar 4.25 maka akan diarahkan menuju halaman beranda ownCloud seperti pada gambar 4.26 dibawah ini

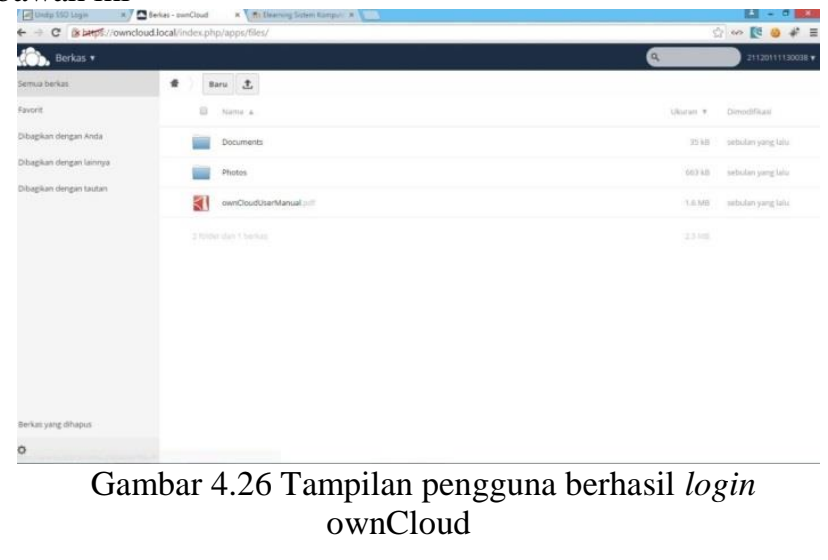

\section{Hasil Impelementasi Plugin}

Pembuatan menghasilkan plugin yang dipasang pada Moodle berada pada direktori local. Sehingga memiliki tipe plugin local. Plugin ini hanya bisa diakses oleh pengguna dengan hak akses Staff Kependidikan, Administrator.

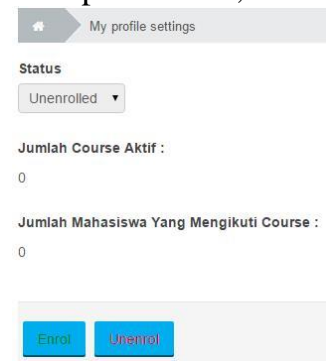

Gambar 4.27 Tampilan plugin sebelum enroll Plugin ini terdapat keterangan seperti dibawah ini :

1. Status, merupakan status apakah mahasiswa didaftarkan kedalam course atau tidak. Status ini terdiri dari dua yaitu Unenerolled, Enrolled. Status Unenrolled ini menjelaskan bahwa mahasiswa tidak didaftarkan pada course Moodle. Sedangkan Enrolled menunjukkan bahwa mahasiswa telah didaftarkan pada course Moodle.

2. Jumlah Course Aktif, menunjukkan jumlah course yang diikuti oleh mahasiswa.

3. Jumlah Mahasiswa Yang Mengikuti Course, menunjukkan jumlah mahasiswa yang mengikuti course. 
Setelah melakukan enroll maka nilai yang sebelumnya berupa angka nol pada plugin akan muncul seperti pada gambar 2.28. Jika mahasiswa mengambil mata kuliah, pada plugin yang telah dibuat akan menghasilkan data berupa berkas XML yang merupakan hasil data dari basis data. Berkas XML ini oleh plugin diberi nama mhsData.XML, jika dibuka akan berisi data seperti gambar 4.29

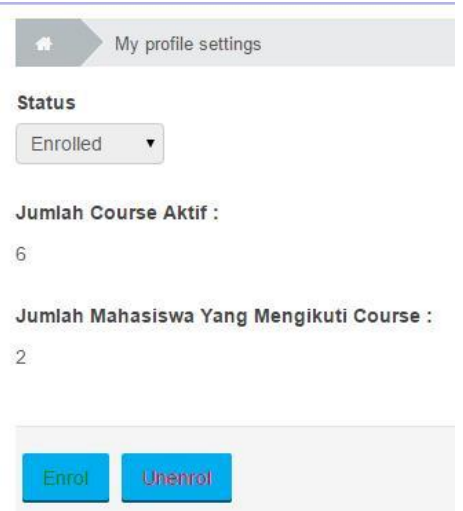

Gambar 4.28 Tampilan plugin setelah enroll

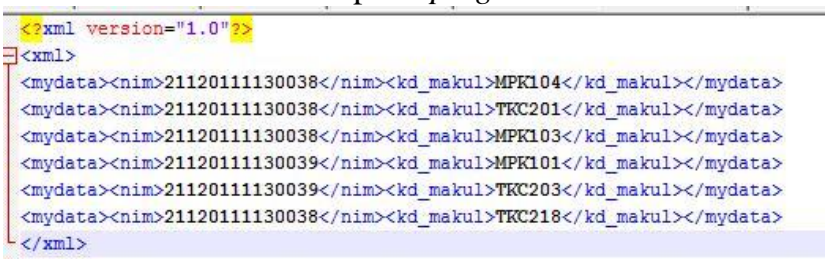

Gambar 4.29 Data mahasiswa mengambil mata kuliah dalam berkas XML.

Data pada gambar 4.29 menunjukkan bahwa terdapat dua buah nilai yang diidentifikasi sebagai nim dan kode makul. Terdapat dua nim yang artinya terdapat dua mahasiswa yang mengambil mata kuliah. Masing-masing mahasiswa mengambil sejumlah mata kuliah yaitu mahasiswa dengan nim 21120111130038 mengambil sebanyak tiga mata kuliah dengan mata kuliah yang memiliki kode mata kuliah berturut-urut MPK104, TKC201, MPK103,TKC218. Sedangkan mahasiswa yang memiliki nim 21120111130039 mengambil sebanyak dua mata kuliah dengan mata kuliah yang memiliki kode mata kuliah berturutturut MPK101, TKC203.

Plugin dapat melakukan fungsi jika pengguna yang memiliki hak akses staff pendidikan melakukan proses enroll. Sehingga mahasiswa yang telah mengambil data tersebut dapat langsung masuk kedalam course Moodle tanpa harus melakukan permintaan enroll pada masing-masing course. Mahasiswa dapat melihat course yang dipilih melalui halaman beranda.

Nim pada Moodle digunakan sebagai username, sehingga untuk mengetahui pemilik nim maka melihat pada tabel mdl_user. Pada kolom firstaname, lastname berisi nama awal dari username begitu juga dengan lastname. Sehingga jika username berisi nim maka nama mahasiswa dapat dilihat pada tabel seperti pada gambar 4.30

\begin{tabular}{|l|l|l|l|}
\hline username & password idnumber & firstname & lastname \\
\hline 21120111130038 & $\begin{array}{l}\text { not } \\
\text { cached }\end{array}$ & $\begin{array}{l}\text { Muhammad } \\
\text { Rozi }\end{array}$ & Yerusalem \\
\hline 21120111130039 & $\begin{array}{l}\text { not } \\
\text { cached }\end{array}$ & Triwibowo \\
\hline
\end{tabular}

Gambar 4.30 Gambar tabel mdl_user

Pada Moodle nama pengguna yang ditampilkan adalah firstname dan lastname bukan username. Sehingga dari dua buah nim tersebut menampilkan mahasiswa seperti pada gambar 4.31 dan gambar 4.32

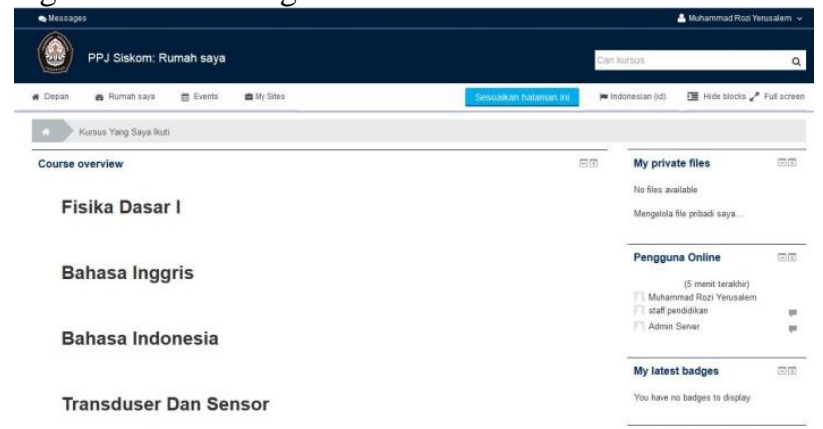

Gambar 4.31 Tampilan daftar course pada halaman beranda mahasiswa nim 21120111130038

Gambar 4.31 menunjukkan daftar course pada Moodle yang telah dipilih sesuai dengan mata kuliah yang dipilih oleh mahasiswa nim 21120111130038 dengan nama Muhammad Rozi Yerusalem. Dari data seperti yang terlihat pada gambar 4.28 yang memiliki kode mata kuliah MPK104, TKC201, MPK103 ditampilkan pada course Moodle berturut turut dengan nama course Bahasa Indonesia, Bahasa Inggris, Fisika Dasar I, Transduser dan Sensor.

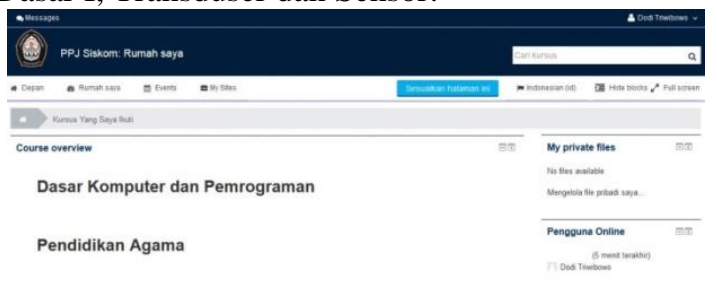

Gambar 4.32 Tampilan daftar course pada halaman beranda nim 21120111130039

Gambar 4.32 menunjukkan daftar course pada Moodle yang telah dipilih sesuai dengan mata kuliah yang dipilih oleh mahasiswa nim 21120111130039 dengan nama Dodi Triwibowo. Dari data seperti yang terlihat pada gambar 4.28 yang memiliki kode mata kuliah MPK101, TKC203, ditampilkan pada course Moodle berturut turut dengan nama course Dasar Komputer dan Pemrograman, Pendidikan Agama.

Pada gambar 4.33 dibawah ini merupakan pengguna dengan hak akses Teacher. Teacher dapat ditambahkan kepada pengguna oleh pengguna yang memiliki hak akses Staff Kependidikan. Dibawah ini merupakan pengguna yang telah diberikan hak akses sebagai Teacher dengan course Transduser dan Sensor. 


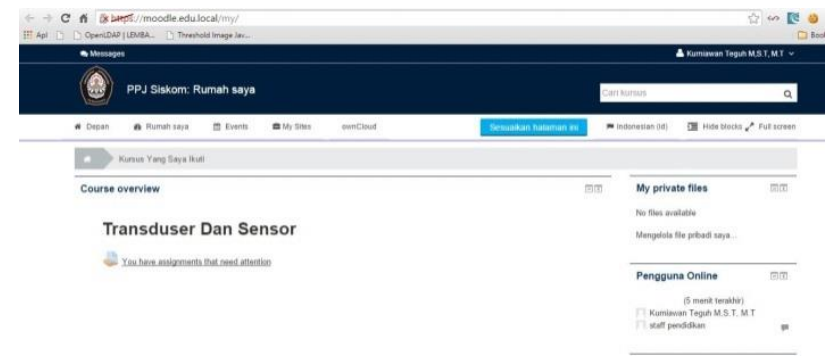

Gambar 4.33 Tampilan daftar course pengguna dengan hak akses Teacher

\section{Tahap Pengujian}

Pengujian sistem menggunakan metode pengujian blackbox. Digunakan untuk menguji fungsi-fungsi khusus dari sistem yang dirancang. Kebenaran pengujian dilihat dari keluaran yang dihasilkan dari data atau kondisi masukan yang diberikan untuk fungsi yang ada tanpa melihat bagaimana proses untuk mendapatkan keluaran tersebut. Dari keluaran yang dihasilkan, kemampuan program dalam memenuhi kebutuhan pemakai dapat diukur sekaligus dapat diketahui kesalahannya. Berikut ini pengujian fungsi dari sistem.

Tabel 4.1 Tabel Pengujian

\begin{tabular}{|c|c|c|}
\hline $\begin{array}{r}\text { Bentuk } \\
\text { Pengujian }\end{array}$ & Hasil Pengujian & $\begin{array}{r}\text { Status } \\
\text { Pengujian }\end{array}$ \\
\hline $\begin{array}{l}\text { Mengakses } \\
\text { http://elearning.sisk } \\
\text { om.local:8443/cas }\end{array}$ & $\begin{array}{ll}\text { Muncul tampilan } \\
\text { login Single Sign On } \\
\text { Server }\end{array}$ & Berhasil \\
\hline $\begin{array}{l}\text { Jika pengguna } \\
\text { mengisikan } \\
\text { Username dan } \\
\text { password, } \\
\text { kemudian } \\
\text { mengklik tombol } \\
\text { Login. }\end{array}$ & $\begin{array}{l}\text { Muncul tampilan } \\
\text { halaman } \\
\text { berisi tautan } w e b\end{array}$ & Berhasil \\
\hline $\begin{array}{l}\text { Pengguna } \\
\text { mengklik tautan } \\
\text { web Moodle }\end{array}$ & $\begin{array}{lr}\text { Pengguna } & \text { diarahkan } \\
\text { menuju } & \text { halaman } \\
\text { Moodle } & \end{array}$ & Berhasil \\
\hline $\begin{array}{l}\text { Pengguna } \\
\text { mengklik tautan } \\
\text { web OwnCloud }\end{array}$ & $\begin{array}{lr}\text { Pengguna } & \text { diarahkan } \\
\text { menuju } & \text { halaman } \\
\text { OwnCloud } & \\
\end{array}$ & Berhasil \\
\hline $\begin{array}{l}\text { Pengguna } \\
\text { mengklik Logout }\end{array}$ & $\begin{array}{l}\text { Pengguna diarahkan } \\
\text { ke halaman login } \\
\text { SSO Server }\end{array}$ & Berhasil \\
\hline $\begin{array}{l}\text { Mengakses } \\
\text { halaman login di } \\
\text { https://moodle.edu. } \\
\text { local/login/index.p } \\
\text { hp }\end{array}$ & $\begin{array}{l}\text { Muncul tampilan } \\
\text { login Single Sign On } \\
\text { Server }\end{array}$ & Berhasil \\
\hline $\begin{array}{l}\text { Jika pengguna } \\
\text { mengisikan } \\
\text { Username dan } \\
\text { password, } \\
\text { kemudian } \\
\text { mengklik tombol } \\
\text { Login. }\end{array}$ & $\begin{array}{l}\text { Muncul } \\
\text { halaman } \\
\text { Moodle }\end{array}$ & Berhasil \\
\hline
\end{tabular}

\begin{tabular}{|c|c|c|}
\hline $\begin{array}{l}\text { Mengakses } \\
\text { halaman login } \\
\text { ownCloud } \\
\text { https://owncloud.lo } \\
\text { cal }\end{array}$ & $\begin{array}{l}\text { Pengguna diarahkan } \\
\text { menuju halaman } \\
\text { beranda ownCloud }\end{array}$ & Berhasil \\
\hline $\begin{array}{l}\text { Mengakses } \\
\text { halaman login } \\
\text { Single Sign On } \\
\text { Server } \\
\text { https://elearning.sis } \\
\text { kom.local:8443/cas }\end{array}$ & $\begin{array}{l}\text { Pengguna diarahkan } \\
\text { menuju halaman } \\
\text { beranda Single Sign } \\
\text { On Server }\end{array}$ & Berhasil \\
\hline $\begin{array}{l}\text { Mengakses } \\
\text { halaman login di } \\
\text { https://owncloud.lo } \\
\text { cal }\end{array}$ & $\begin{array}{l}\text { Muncul tampilan } \\
\text { login Single Sign On } \\
\text { Server }\end{array}$ & Berhasil \\
\hline $\begin{array}{l}\text { Jika pengguna } \\
\text { mengisikan } \\
\text { Username dan } \\
\text { password, } \\
\text { kemudian } \\
\text { mengklik tombol } \\
\text { Login. }\end{array}$ & $\begin{array}{l}\text { Pengguna diarahkan } \\
\text { menuju halaman } \\
\text { beranda OwnCloud }\end{array}$ & Berhasil \\
\hline $\begin{array}{l}\text { Mengakses } \\
\text { halaman login } \\
\text { Moodle di } \\
\text { https://moodle.edu. } \\
\text { local/login/index.p } \\
\text { hp }\end{array}$ & $\begin{array}{l}\text { Pengguna diarahkan } \\
\text { menuju halaman } \\
\text { beranda Moodle }\end{array}$ & Berhasil \\
\hline $\begin{array}{l}\text { Mengakses } \\
\text { halaman login } \\
\text { Moodle di } \\
\text { https://moodle.edu. } \\
\text { local/login/index.p } \\
\text { hp }\end{array}$ & $\begin{array}{l}\text { Pengguna diarahkan } \\
\text { menuju halaman } \\
\text { beranda Moodle }\end{array}$ & \\
\hline $\begin{array}{l}\text { Mengakses } \\
\text { halaman login } \\
\text { Single Sign On } \\
\text { Server } \\
\text { https://elearning.sis } \\
\text { kom.local:8443/cas }\end{array}$ & $\begin{array}{l}\text { Pengguna diarahkan } \\
\text { menuju halaman } \\
\text { beranda Single Sign } \\
\text { On Server }\end{array}$ & Berhasil \\
\hline \begin{tabular}{lr}
\multicolumn{2}{l}{ Pengguna dengan } \\
hak akses staff \\
kependidikan
\end{tabular} & $\begin{array}{lr}\text { Muncul tampilan } \\
\text { plugin } & \text { staff } \\
\text { kependidikan } & \end{array}$ & Berhasil \\
\hline $\begin{array}{l}\text { Pengguna dengan } \\
\text { hak akses staff } \\
\text { kependidikan } \\
\text { mengklik tombol } \\
\text { enrol }\end{array}$ & $\begin{array}{lr}\text { Muncul status } \\
\text { Enrolled, jumlah } \\
\text { courses yang diikuti } \\
\text { mahasiswa, jumlah } \\
\text { mahasiswa yang } \\
\text { mengikuti courses. }\end{array}$ & Berhasil \\
\hline $\begin{array}{l}\text { Pengguna } \\
\text { mengklik tombol } \\
\text { unenrol }\end{array}$ & $\begin{array}{l}\text { Muncul status } \\
\text { Unenrolled, jumlah } \\
\text { courses yang diikuti } \\
\text { mahasiswa } 0, \text { jumlah } \\
\text { mahasiswa yang } \\
\text { mengikuti courses } 0 .\end{array}$ & Berhasil \\
\hline
\end{tabular}




\section{Penutup}

\section{Kesimpulan}

Berdasarkan hasil analisis dan pengujian blackbox kesimpulan pada sistem pembelajaran jarak jauh adalah sebagai berikut :

1. Pembuatan sistem pembelajaran jarak jauh yang berbasis single sign on telah berhasil diimplementasikan dengan menggunakan CAS Server dan LDAP Server Universitas Diponegoro.

2. Otentikasi menggunakan akun yang dimiliki pada sistem informasi akademik program studi Sistem Komputer berhasil masuk kedalam SSO Server, Moodle, dan Owncloud dengan sekali login.

3. Pembuatan plugin Moodle berhasil memasukkan mahasiswa yang mengambil mata kuliah sesuai dengan KRS kedalam course Moodle. Proses memasukkan mahasiswa ke dalam course Moodle membutuhkan informasi unik yaitu dapat berupa NIM dan kode mata kuliah yang diambil oleh mahasiswa dari sistem informasi akademik.

\section{Saran}

Saran untuk mengembangkan sistem yang lebih baik adalah sebagai berikut :

1. Penelitian terhadap pemanfaatan sistem dengan memanfaatkan purwarupa yang telah dibangun.

2. Plugin dapat dikembangkan untuk memasukkan mahasiswa kedalam course berdasarkan kelas.

3. Sistem dapat ditambahkan dengan sistem single sign out.

\section{DAFTAR PUSTAKA}

[1] Amiroh., Kupas Tuntas Membangun E-Learning dengan Learning Management System Moodle.,Genta Group, Sidoarjo, 2012.

[2] A.S, Rosa dan M. Shalahuddin., Modul Pembelajaran Rekayasa Perangkat Lunak, Modula, Bandung, 2011.

[3] CAS4.0.xArchitecture.http://jasig.github.io/cas/4.0.x/pla nning/Architecture.html, 18 Maret 2015, 09.45 WIB

[4] Hursti, Jani. Single Sign On. Department of Computer Science Helsinki University of Technology. 1997.

[5] Introduction.http://dev.mysql.com/doc/refman/5.5/en/in troduction.html 17 Maret 2015, 13.40 WIB.

Introduction to OpenLDAP Directory Services,

[6] http://www.openldap.org/doc/admin20/intro.html\#What is a directory service, 14 Maret 2015, 08.00 WIB.

[7] Intro What Is PHP. http://id1.php.net/manual/en/introwhatis.php 15 Maret 2015, 10.30 WIB.

[8] Munir., Pembelajaran Jarak Jauh Berbasis Online dan Web, Universitas Pendidikan Indonesia, 2012.

[9] OwnCloud.,https://doc.ownCloud.org/server/8.0/admin _manual/index.html\#introduction 1 April, 15.30 WIB.

[10] Putera, Satya Fibrian R., Sistem Otentikasi Terpusat Berbasis Lighweight Directory Access Protocol, Universitas Diponegoro, 2011.
[11] Ray, Erik T., Learning XML. O'reilly Media, Inc, United States of America, 2003.

[12] Sailah, Illah., Panduan Penyelenggaraan Model Pembelajaran Pendidikan Jarak Jauh di Perguruan Tinggi. Kementerian Pendidikan Nasional Direktorat Jenderal Pendidikan Tinggi Direktorat Pembelajaran dan Kemahasiswaan, Jakarta, 2011.

[13] Saputro., Muhammad Yanuar Ali., Implementasi Sistem Single Sign On/Single Sign Out Berbasis Central Authentication Service Protocol Pada Jaringan Berbasis Lightweight Directory Access Protocol, Universitas Diponegoro, 2012

[14] Suranto, B., 2009. Virtual Classroom: Strategi Pembelajaran Berbasis Synchronous E-Learning. Makalah yang disajikan pada Seminar Nasional Aplikasi Teknologi Informasi 2009 (SNATI 2009) Yogyakarta. http://journal.uii.ac.id/index.php/Snati/ article/view/1221/1009. 6 September 2015, 19.58 WIB

[15] Tim BELMAWA DIKTI., Buku Panduan Kurikulum Pendidikan Tinggi. Direktorat Pembelajaran dan Kemahasiswaan Direktorat Jenderal Pendidikan Tinggi Kementerian Pendidikan dan Kebudayaan, Jakarta, 2014.

[16] Triluqman, Heri dan Sukirman., Pengembangan Sistem Pembelajaran Online Berbasis Moodle Di Jurusan Kurikulum Dan Teknologi Pendidikan Universitas Negeri Semarang, Universitas Negeri Semarang, 2009. 